\title{
Quasi-stable temperature of the steady state of microwave heated hematite
}

\section{$\operatorname{AUTHOR}(S)$ :}

Kashimura, K.; Sabelstrom, N.; Imazeki, K.; Takeda, K.; Hayashi, M.; Mitani, T.; Shinohara, N.; Nagata, K.

\section{CITATION:}

Kashimura, K.... [et al]. Quasi-stable temperature of the steady state of microwave heated hematite. Chemical Engineering and Processing: Process Intensification 2014, 76: 1-5

\section{ISSUE DATE:}

2014-02

URL:

http://hdl.handle.net/2433/185143

\section{RIGHT:}

(c) 2013 Elsevier B.V.; この論文は出版社版でありません。引用の際には 出版社版をご確認ご利用ください。; This is not the published version. Please cite only the published version. 


\title{
Quasi-Stable Temperature of the Steady State of Microwave Heated Hematite
}

K. Kashimura ${ }^{1}$, N. Sabelstrom ${ }^{2}$, K. Imazeki² ${ }^{2}$ K. Takeda ${ }^{2}$, M. Hayashi ${ }^{2}$, T. Mitani $^{1}$, N. Shinohara ${ }^{1}$ and K. Nagata ${ }^{3}$

1. Kyoto University, Gokasyo, Uji, Kyoto 611-0011, Japan

2. Tokyo Institute of Technology, Ookayama 2-12-1, Meguro, Tokyo 152-8552, Japan

3. Tokyo University of the Arts, 12-8 Ueno Kouen, Taito-ku, Tokyo 110-8714 Japan

\begin{abstract}
Microwave heated materials often reach a quasi-stable temperature resulting in thermal runaway. To control the quasi-stable temperature in microwave processing, it is important to predict the quasi-stable temperature of the steady state. We demonstrated that the microwave heating behavior of hematite varies significantly with its initial temperature. In microwave heating experiments, the temperature of hematite that had not been preheated did not increase, whereas hematite that had been preheated to 410 ${ }^{\circ} \mathrm{C}$ or higher was heated to a temperature of $1020{ }^{\circ} \mathrm{C}$. The microwave heating behavior can be accurately predicted by considering the steady-state energy balance.
\end{abstract}

Keywords: [metal oxides, $2.45 \mathrm{GHz}$, microwave processing, hematite, stability of processing] 


\section{INTRODUCTION}

Microwave heating has been attracting great interest as a new means of supplying energy to processes. Microwave heating can produce metal sintered compacts that differ from conventional ones due to the generation of nonequilibrium temperatures on the microscale [1-6]. Ishizaki and Nagata [2] constructed a high-power $(12 \mathrm{~kW})$ continuous $2.45-\mathrm{GHz}$ microwave furnace and Peng et al. [3] constructed a $915-\mathrm{MHz}, 225-\mathrm{kW}$ microwave furnace to scale up steel production. The above mentioned studies all used microwave energies, resulting in rapid chemical synthesis. Microwave heating of powder compacts has been studied for several decades with a view to applying such a technique to industrial processes. Cheng et al. [7] compared the heating rates of metals, ceramics, and metal-ceramic composites in different microwave fields. They found that the magnetic component cannot be ignored when considering the energy loss in metals subjected to a microwave field. Ma et al. [8] systematically investigated the absorption and heating characteristics and the microstructural evolution of porous copper powder metal compacts irradiated with $2.45-\mathrm{GHz}$ microwaves. They observed the heating characteristics of copper particles with various radii. The above studies [7-9] demonstrate that the Mie theory for a single particle can account for the high heating rates generated by the microwave magnetic field in microwave sintering experiments.

In contrast, few studies have used stability theory to predict the steadystate temperature of microwave heating despite the importance of steadystate temperature prediction for industrial processing. To realize efficient microwave processing, the temperature of high temperature in the steady 
state (i.e., the thermal runaway) should be predicted (In this paper, this temperature is defined as the quasi-stable temperature). However, two problems need to be overcome to make this possible. The first is the scarcity of data for the absorption properties as a function of temperature. Most measurements of microwave absorption properties have been performed at temperatures near room temperature. The absorption properties of materials like ceramics change drastically at high temperatures [10-11], which greatly affects the steady-state temperature. The absorption properties of a material need to be known to accurately predict steady-state temperatures. The second problem is the difficultly in constructing a high-power microwave applicator. It is in the microwave heating behavior of a poor microwave absorber that a quasi-steady temperature is likely to be observed. However, it is difficult to heat poor absorbers using pure microwaves.

In the present study, we experimentally demonstrate that the microwave heating behavior of high-power microwave applicators can be predicted by considering the steady-state energy balance. We first investigate the temperature dependence of the microwave absorption properties of hematite at frequencies in the range $1-13.5 \mathrm{GHz}$ (hematite is considered to be a poor microwave absorber; we selected hematite to observe the quasi-steady-state temperature). Using a system whose reaction system is separate from the heating system, we found that the heating behavior of hematite varies significantly with its initial temperature. 


\section{EXPERIMENTAL PROCEDURE}

\subsection{ABSORPTION PROPERTIES OF HEMATITE}

This study used hematite powder consisting of $0.5-\mu$ m-diameter $\alpha-\mathrm{Fe}_{2} \mathrm{O}_{3}$. The real and imaginary parts of the relative permittivity $\left(\epsilon_{r}^{\prime}\right.$ and $\left.\epsilon_{r}^{\prime \prime}\right)$ were measured over the temperature range $25-1000{ }^{\circ} \mathrm{C}$ by the coaxial transmission line method using a network analyzer (Agilent Technologies, N5230A), coaxial cables, and an APC7 coaxial sample holder over a microwave frequency range of 1-13.5 GHz (see Fig. 1). Using an electric resistance furnace, the temperature was increased at a rate of $10{ }^{\circ} \mathrm{C} / \mathrm{min}$ during measurements. The transmission and reflection (S parameters) of the irradiated microwaves were measured about every $50{ }^{\circ} \mathrm{C}$ during the heating cycle. The network analyzer had an output power of ca. $1 \mathrm{~mW}$. Each measurement was performed over a frequency range of $1-13.5 \mathrm{GHz}$ and took about $2 \mathrm{~s}$. The complex permittivity was calculated from the S parameters using the algorithm of the NIST precision method [12].

The compressions were applied to both sides of the powder and the compacts were fixed to a volume of $\phi 3.04 \times 7 \mathrm{~mm}^{3}$ in this measurement. Because hematite particles have a diameter of $0.5 \mu \mathrm{m}$ and a weight of $0.875 \mathrm{~g}$, this device made compacts with a constant relative density of $1.75 \mathrm{~g} / \mathrm{cm}^{3}$.

In this experiment, the sample was heated using an electric resistance furnace. The heat was generated in an isolated furnace, meaning there was some latency in terms of the heat reaching the center of the coaxial chamber. The temperature was measured by a thermocouple attached to the outer wall of the holder instead of a thermocouple embedded in the sample (the heating rate was $10{ }^{\circ} \mathrm{C} / \mathrm{min}$ ). The measured temperatures were hence indicated 
temperatures, so calibration was necessary to obtain the true temperatures. To calibrate the outer thermocouple, the apparent and true temperatures were measured simultaneously during a heating cycle using an additional thermocouple embedded in the sample.

\subsection{HEATING SYSTEM}

Figure 2 shows a schematic diagram of the microwave applicator used. This applicator has a $2.45-\mathrm{GHz}$ magnetron oscillator $(\times 8)$, an isolator, WRJ2 waveguides, stirrers, and a furnace body. The magnetrons generate 2.45 $\mathrm{GHz}$ microwaves at a total output power of $12 \mathrm{~kW}(1.5 \times 8 \mathrm{~kW})$. The body consists of a hexagonal cylinder and a half sphere $(\times 2)$; these shapes focus microwaves onto the sample. In this system, the reaction system is separate from the heating system. The sample was preheated by an electric furnace to a sufficiently high temperature and microwaves $(3 \mathrm{~kW})$ were focused onto the sample, as shown in Fig. 2. In these experiments, carbon and magnetite powders were also employed as samples for comparison with hematite.

\section{RESULTS AND DISCUSSION}

\subsection{ABSORPTION PROPERTIES}

Before discussing the quasi-stable temperature of the steady state during microwave heating, we must understand the absorption properties. Figures 3(a)-(e) show plots of the real and imaginary parts of the relative permittivity $\left(\epsilon_{r}^{\prime}\right.$ and $\left.\epsilon^{\prime \prime}{ }_{r}\right)$ of $\alpha-\mathrm{Fe}_{2} \mathrm{O}_{3}$ powders (particle size: $0.5 \mu \mathrm{m}$; relative density: 1.75 $\mathrm{g} / \mathrm{cm}^{3}$ ) as a function of temperature for frequencies of $1,2.45,57.5,10$, and 13.5 GHz, respectively. At all frequencies, $\epsilon{ }_{r}$ was observed to increase with 
increasing temperature at temperatures of $800{ }^{\circ} \mathrm{C}$ or lower. Since ceramics are highly conductive in this temperature, the permittivity of the $\alpha-\mathrm{Fe}_{2} \mathrm{O}_{3}$ powder is $\epsilon^{\prime \prime}{ }_{r} \approx(\sigma / \omega) \times i$ (where $\sigma$ is the static electrical conductivity and $\mathrm{i}$ was the current from the electrical gradient). The increase in $\epsilon{ }_{r}$ must be due to an increase in the electrical conductivity, considering that there were no chemical reactions in this experiment. Some researchers reported anomalous behaviors of chemical reactions even though the phase diagram indicates that hematite is stable at high oxygen partial pressures. We did consider the possibility of permeability changes due to chemical reactions; however, we removed this possibility by measuring the stability of hematite in air using XRD at high temperatures; no reaction was observed. As a result of this, we thought that $\mathrm{Fe}_{2} \mathrm{O}_{3}$ exhibits metallic behavior at the present microwave frequencies due to the high free electron density near the Fermi level at temperatures of $800{ }^{\circ} \mathrm{C}$ and higher. Consequently, $\epsilon{ }_{r}$ decreases with increasing temperature above $800{ }^{\circ} \mathrm{C}$ (see Refs. 9, 11, and 13-14 for detailed descriptions of the mechanism in terms of polarization and polaritons).

\subsection{METASTABLE TEMPERATURE IN MICROWAVE HEATING}

Steady-state theory predicts metastable temperatures in the steady state for microwave heating. Considering the above results, we regard the input and output powers as functions of temperature. The input power of the hematite powder compact per volume is given by

$$
w_{i n}(T)=\int_{V} \frac{1}{2}\left(\omega \epsilon^{\prime \prime}(T)|E|^{2}+\omega \mu^{\prime \prime}(T)|H|^{2}\right) d V
$$

, where $w_{\text {in }}(T)$ is the input power per volume at the observation point (note another form of eq. (1) includes the energy transition induced by the cur- 
rent; in this paper, we employ the above form $), \epsilon^{\prime \prime}(T)$ is the imaginary part of the dielectric permittivity $\left(N / V^{2}\right), \mu^{\prime \prime}(T)$ is the magnetic permeability $\left(N / A^{2}\right), \mathrm{E}($ or $\mathrm{H})$ is the electric (or magnetic) intensity $(\mathrm{V} / \mathrm{m}$ or $\mathrm{A} / \mathrm{m})$, and $\omega$ is the angular frequency ( $\mathrm{rad} / \mathrm{sec}$ ) of electromagnetic field. For hematite, the second term in eq. (1) is negligible so that $w_{i n}(T)$ is proportional to $\epsilon^{\prime \prime}(T)$ (permittivity $>>$ permeability) [15]. Assuming that hematite does not modify the electric field strength, the temperature dependence of $w_{\text {in }}(T)$ is entirely contained in $\epsilon^{\prime \prime}(T)$ (in this paper, the integral was taken to be the total input energy for a sample, $P_{i n}(T)$ ). In contrast, the substrate energy from a hematite powder compact is given by

$$
w_{\text {out }}(T)=\int_{S} h\left(T-T_{\text {air }}\right) d S+\frac{d}{d t} \int_{V} \int \rho C(T) d T d V+\int_{S} \theta \delta\left(T^{4}-T_{\text {sur }}^{4}\right) d S
$$

, where $\mathrm{h}$ is the heat transfer coefficient $\left(\mathrm{Wm}^{-2} \mathrm{~K}^{-1}\right), T_{\text {air }}$ is the temperature of air $(\mathrm{K}), T_{\text {sur }}$ is the surrounding wall temperature $(\mathrm{K}), C(T)$ is the heat capacity at constant volume $\left(\mathrm{Jmol}^{-1} \mathrm{~K}^{-1}\right), \delta$ is the Stefan-Boltzmann constant $\left(=5.67 \times 10^{-8} W^{-2} K^{-4}\right), \theta$ is the emissivity $(=0.96), \mathrm{t}$ is time $\left(\sec ^{-1}\right)$, and $\rho$ is the molar $\operatorname{density}\left(\operatorname{mol~} m^{-3}\right)$. When $w_{\text {in }}(T)=w_{\text {out }}(T)$, the second term on the right-hand side of eq. (2) is nearly zero. The third term on the right-hand side of eq. (2) affects $w_{\text {out }}(T)$ at high temperatures; hematite exhibits a nonlinear relationship between $w_{\text {out }}(T)$ and temperature in this temperature range.

Figure 4 shows a schematic plot of $P_{\text {out }}$ (black line) and $P_{\text {in }}$ for a poor absorber like hematite (red line) and a good absorber like magnetite or carbon (blue line) as a function of temperature. In this figure, the $P_{\text {in }}$ curves are for non-magnetic materials. For poor absorbers, $P_{\text {in }}=P_{\text {out }}$ at temperatures of 
Ta, Tb, and Tc. As Fig. 4 shows, $P_{\text {in }}<P_{\text {out }}$ at $T$ ', whereas $P_{\text {in }}>P_{\text {out }}$ at $T$ ". Hematite exhibits a steady temperature between $T a$ and $T c$. In contrast, hematite exhibits chaotic heating behavior at $T b$. Hematite is expected to exhibit an unsteady temperature at this temperature. For absorbers, $P_{\text {in }}>$ $P_{\text {out }}$ at temperatures lower than that indicated by the blue circle in Fig. 4. In this region, the excess energy causes the temperature to vary greatly, as indicated by the blue circle.

Here, we will introduce a comparison of the concept illustrated in Fig. 4 with experiment results. Figures 5(a)-(b) show plots of the temperature over time for hematite and preheated hematite for different particle sizes. Microwave absorbers such as graphite and magnetite powder compacts exhibit steady temperatures without preheating (carbon powders showed maximum microwave absorption at $1000{ }^{\circ} \mathrm{C}$ or higher [16]). For the case, $P_{\text {in }}>P_{\text {out }}$ at any temperature below that indicated by the blue circle in Fig. 4 and the concept accounts for phenomena well. In this experiment poor absorbers exhibited the predicted heating behavior, which was dependent on the temperature range. Preheated hematite exhibits a temperature dependence different to that of hematite that was not preheated. The temperature of hematite that had not been preheated did not increase because it did not gain sufficient energy to be heated by the electric field. In contrast, hematite that had been preheated to a temperature of $410-600{ }^{\circ} \mathrm{C}$ or greater was microwave heated to a temperature of $1020-1220{ }^{\circ} \mathrm{C}$. In this case, hematite gained sufficient energy to be heated by the electric field. $T b$ and $T c$ can be predicted by steady-state theory. Using eqs. (1) and (2), Tc was estimated to be $1080-1100{ }^{\circ} \mathrm{C}$ (where $\mathrm{V}=3.38 \times 10^{-5} \mathrm{~m}^{3}, \mathrm{~S}=6.45 \times 10^{-3} \mathrm{~m}^{2}, \theta=0.96, \mathrm{~h}=75.8 \mathrm{Wm}^{-2} \mathrm{~K}^{-1}$, 
$T_{\text {air }}=25^{\circ} \mathrm{C}$, and $T_{\text {sur }}=25^{\circ} \mathrm{C}$ ) and the relation $|E|^{2}=\sqrt{\frac{\mu}{\epsilon}} W_{m w} \mathrm{~F} / \mathrm{m}$ was employed to convert $\mathrm{W}_{m w}$ (Microwave power) to $\mathrm{E}$ [17]. The estimated values for $T c$ agree well with the experimentally measured values. Steady-state theory predicts that ceramics with poor absorption properties can be heated to a high temperature; it is also useful for predicting the steady-state temperature in microwave processing. Considering that we used XRD during the microwave irradiation and no magnetite peaks were observed, the application of the concept is adequate and the concept describes the phenomena well.

However, the estimated value of $\mathrm{Tb}\left(680^{\circ} \mathrm{C}\right)$ differs greatly from the measured value $\left(410-600{ }^{\circ} \mathrm{C}\right)$. This is because the estimation was based on a model in which the temperature distribution is assumed to be uniform within the material. Microwaves generate micro-hot spots, which have higher temperatures than other places. These micro-hot spots generate higher temperatures in their vicinity because they are selectively heated. Further studies are needed to address the micro-hot spots quantitatively. 


\section{SUMMARY}

We experimentally demonstrated the temperature behavior in given temperature ranges for microwave heated materials and observed the existence of quasi-stable-state temperature in microwave heating. Applying high-power microwaves, the temperature of hematite that had not been preheated did not increase, whereas hematite that had been preheated to $410-600{ }^{\circ} \mathrm{C}$ or higher was heated to a temperature of $1020-1220{ }^{\circ} \mathrm{C}$. This is because the preheated hematite gained sufficient energy to be heated by the electric field due to its good absorption. To predict the heating behavior, we investigated the temperature dependence of the absorption properties of hematite at microwave frequencies in the range of $1-13.5 \mathrm{GHz}$. The microwave heating behavior can be accurately predicted by considering the steady-state energy balance and we found that the heating behavior and properties of hematite vary significantly with initial temperature.

To control thermal runaway in microwave processing, it is important to predict the quasi-stable-state temperature. From these results, we confirmed that the microwave heating behavior of hematite varies significantly with initial temperature as predicted by the theory and models. This theory is useful for determining the process temperature for microwave processing.

\section{Acknowledgments}

One of the authors (K. K.) is very grateful to M. Sato, M. Tanaka, M. Ignatenko, K. Fujisaki and D. Agrawal for fruitful discussions. This work was supported by the Research Institute for Sustainable Humanosphere, Kyoto University (project: Mission Research, ADAM, METLAB) and the Environ- 
ment Research and Technology Development Fund (ZF-1203) of the Ministry of the Environment, Japan. 


\section{REFERENCES}

[1] R. Roy, D. Agrawal, J. Cheng and S. Gedevanshvili: Nature, 399 (1999) 668

[2] K. Ishizaki and K. Nagata: ISIJ International, 47, 6 (2007) 811-816

[3] Z. Peng, J. Y. Hwang, M. Andriese, W. Bell, X. Huang and X. Wang: ISIJ International, 51, 6 (2011) 884-888

[4] W. Sutton: Am. Ceram. Soc. Bull 68, 2, (1989) 376-86

[5] J. H. Booske, R. F. Cooper, S. A. Freeman: Mater. Res. Innovat. 1 (1997) $77-84$

[6] N. Yoshikawa, E. Ishizuka, K. Mashiko, S. Taniguchi: Mater. Lett. 61 (2007) 2096-2099

[7] J. Cheng, R. Roy, D. Agrawal: Journal of Materials Science Letters, 20 (2001) 1561-1563

[8] J. Ma, J. F. Diehl, E. J. Johnson, K. R. Martin, N. M. Miskovsky, C. T. Smith, G. J. Weisel, B. L. Weiss and D. T. Zimmermana: Journal of Applied Physics, 101 (2007) 074906

[9] K. Kashimura, S. Suzuki, M. Hayashi, T. Mitani, K. Nagata and N. Shinohara: Journal of Applied Physics., 112, 3 (2012) 034905

[10] M. Hotta, M. Hayashi, A. Nishikata and K. Nagata: ISIJ International, 49, 9 (2009) 1443-1448

[11] Z. Peng, J. Hwang, J. Mouris, R. Hutcheon and X. Huang: ISIJ International., 50, 11 (2010) 1590-1596

[12] J. B. Jarvis: Transmission/Reflection and Short-circuit Line Permittivity Measurements, NIST (1990) [http://www.nist.gov/pml/, Access: 2012-10-18] 
[13] R. Roy, P. Peelamedu, L. Hurtt, J. P. Cheng and D. Agrawal: Materials Research Innovations, 6 (2002) 128-140

[14] M. Hotta, M. Hayashi and K. Nagata: ISIJ International, 51, 3 (2011) 491-497

[15] Supporting information: This is a very common assumption used when measuring samples that are thought to be non-magnetic. These measurements do however take into account the possibility of non-zero magnetic permeability, but these results seem to never have been saved for high temperature measurements. In house measurements at room temperature shows an imaginary effective permeability of less than background $(<0.1$ at $2.45 \mathrm{GHz})$. Similar results at higher temperatures are shown by Peng et al. : ISIJ International, Vol. 52 (2012), No. 9, pp. 1535-1538

[16] M. Hayashi, K. Takeda, K. Kashimura T. Watanabe and K. Nagata: Carbothermic reduction of hematite powders by microwave heating, ISIJ International, Vol. 53, 7 (2013) 1125-1130

[17] Supporting information: Supplement Figure indicates heating behavior of cooling in this apparatus. Parameters for $P_{\text {out }}(\theta=0.96, \mathrm{~h}=75.8$ $\mathrm{Wm}^{-2} \mathrm{~K}^{-1}$ ) were estimated from this behavior. In this estimations, $\mathrm{h}$ were estimated from the cooling behavior of low temperature and $\theta$ were from that of high temperature because $P_{\text {out }}$ are described by eq. (2). In this case, the forward and reflect power meters have a large margin of error because closed systems focuses microwave on (or away from) the power meter. We gave no credence to information that the reflected wave showed less than 10 $\%$ of input in their powers and employed traveling wave approximation for this estimation. 


\section{FIGURE CAPTIONS}

FIG. 1: Setup used to measure the relative permittivity. The sample holder is made of SUS316L stainless steel and is $300 \mathrm{~mm}$ long. An R-type thermocouple was attached to the sample holder using Pt wire. The apparent temperature (Tapp) varies almost linearly with the true temperature (Ttrue) according to Tapp $=$ Ttrue $\times 1.0313+43.237$. This equation was used to correct the temperature for all data.

FIG. 2: Schematic diagram of the microwave applicator. The magnetrons generate $2.45 \mathrm{GHz}$ microwaves with a total output power of $12 \mathrm{~kW}(1.5 \times 8$ $\mathrm{kW}$ ). The applicator chamber in the shape of a hexagonal cylinder was closed by two half spheres; this shape promotes focusing of the microwaves onto the sample. In this experiment, $3 \mathrm{~kW}$ microwaves were applied to the sample. The samples, which were in a reaction room, were separated from the heating system using quartz tubes (quartz A, I.D.: $46 \mathrm{~mm}$ ) and the temperature of the chamber was maintained by thermal insulation around the tubes.

FIG. 3: Temperature dependences of the relative complex permittivity $\left(\epsilon_{r}^{\prime}\right.$ and $\left.\epsilon^{\prime \prime}{ }_{r}\right)$ of $\alpha-\mathrm{Fe}_{2} \mathrm{O}_{3}$ powder (particle size: $0.5 \mu \mathrm{m}$; relative density: 1.75 $\mathrm{g} / \mathrm{cm}^{3}$ ) at frequencies of (a) 1, (b) 2.45, (c) 5, (d) 7.5, (e) 10, and (f) 13.5 GHz. At all frequencies, $\epsilon^{\prime \prime}{ }_{r}$ was observed to increase with increasing temperature at temperatures of $800{ }^{\circ} \mathrm{C}$ or lower. At high temperature, hematite' s absorption properties decrease similarly to metal.

FIG. 4: Schematic illustration of Pout (black line) and Pin for a poor 
absorber such as hematite (red line) and a good absorber such as magnetite and carbon (blue line). For poor absorbers, $P_{\text {in }}=P_{\text {out }}$ at $T a, T b$, and $T c$. The material temperature rises from $T a$ to $T b$ during which time $P_{\text {in }}<P_{\text {out }}$ $\left(T^{\prime}\right)$. Between $T b$ and $T c P_{\text {in }}>P_{\text {out }}\left(T^{\prime},\right)$. For absorbers, $P_{\text {in }}>P_{\text {out }}$ at temperatures lower than that indicated by the blue circle. In this region, the excess energy causes the temperature to vary greatly, as indicated by the blue circle.

FIG. 5: Temperature against time for hematite and preheated hematite with particle sizes of 300-600 $\mu \mathrm{m}$ (a) and 38-75 $\mu \mathrm{m}$ (b). For the particles 300-600 $\mu \mathrm{m}$ in size, hematite that had not been preheated did not increase in temperature, whereas hematite preheated to $480{ }^{\circ} \mathrm{C}$ or higher was heated to $1020^{\circ} \mathrm{C}$. This is because the absorption of the preheated hematite was sufficiently high, meaning that it could be heated by the electric field. The microwave heating behavior of hematite varies significantly with its initial temperature as predicted by the theory. For particles of $38-75 \mu \mathrm{m}$ in size, $\mathrm{Tb}$ took a different value: $410{ }^{\circ} \mathrm{C}$ or higher.

Supplemental Figure: Cooling behavior in this apparatus. We measured the properties of the microwave heating system to estimate the substrate energy. In this experiment, the microwaves were turned off after 212 sec. Parameters for $P_{\text {out }}\left(\theta=0.96, \alpha=75.8 \mathrm{Wm}^{-2} \mathrm{~K}^{-1}\right)$ were estimated from this behavior. 
Figure(s)

Click here to download Figure(s): Figure1.eps

Fig. 1 Kashimura et al.

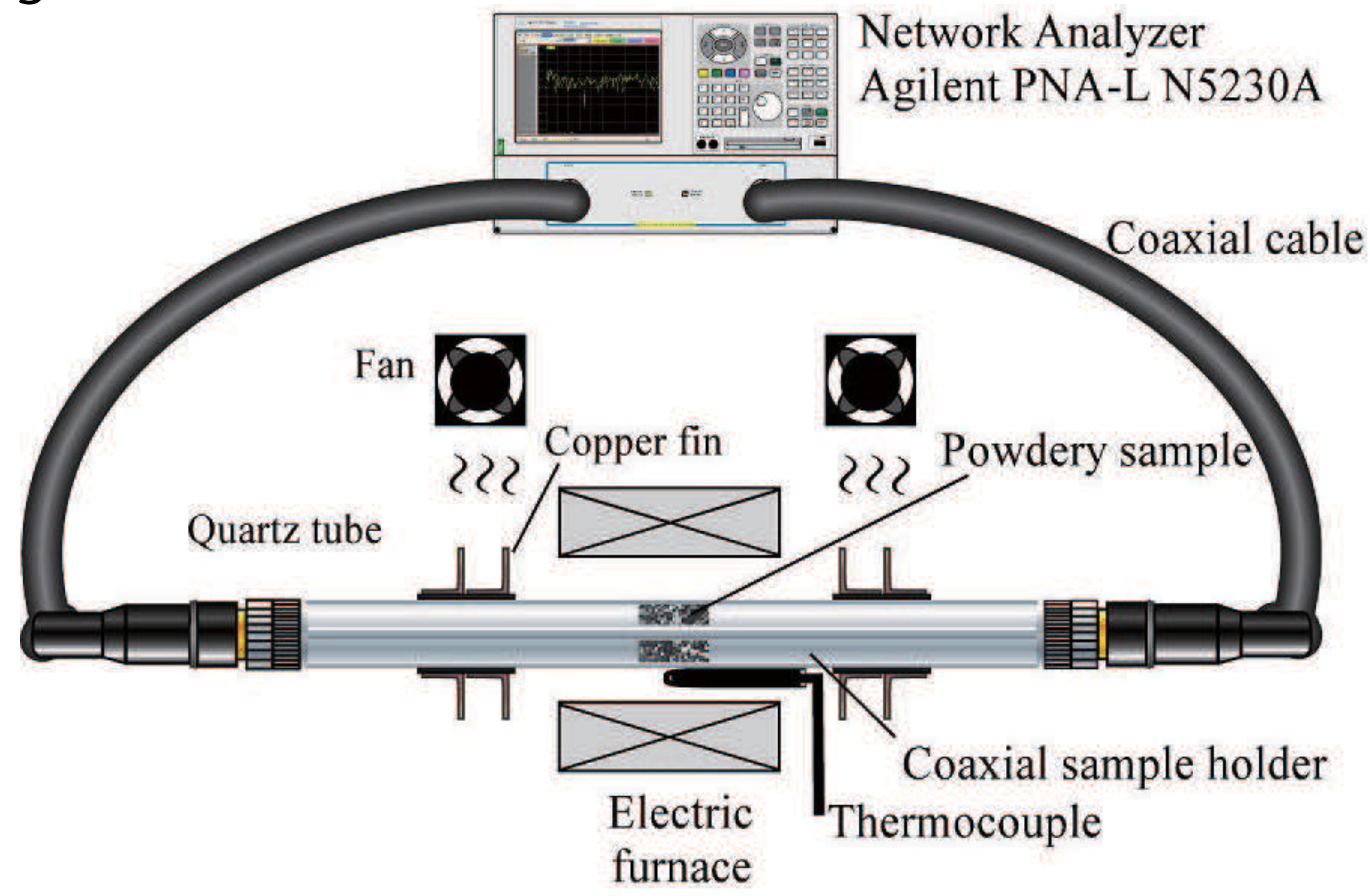


Figure(s)

Click here to download Figure(s): figure2.eps

\section{Fig. 2 Kashimura et al.}

Microwave Applicator
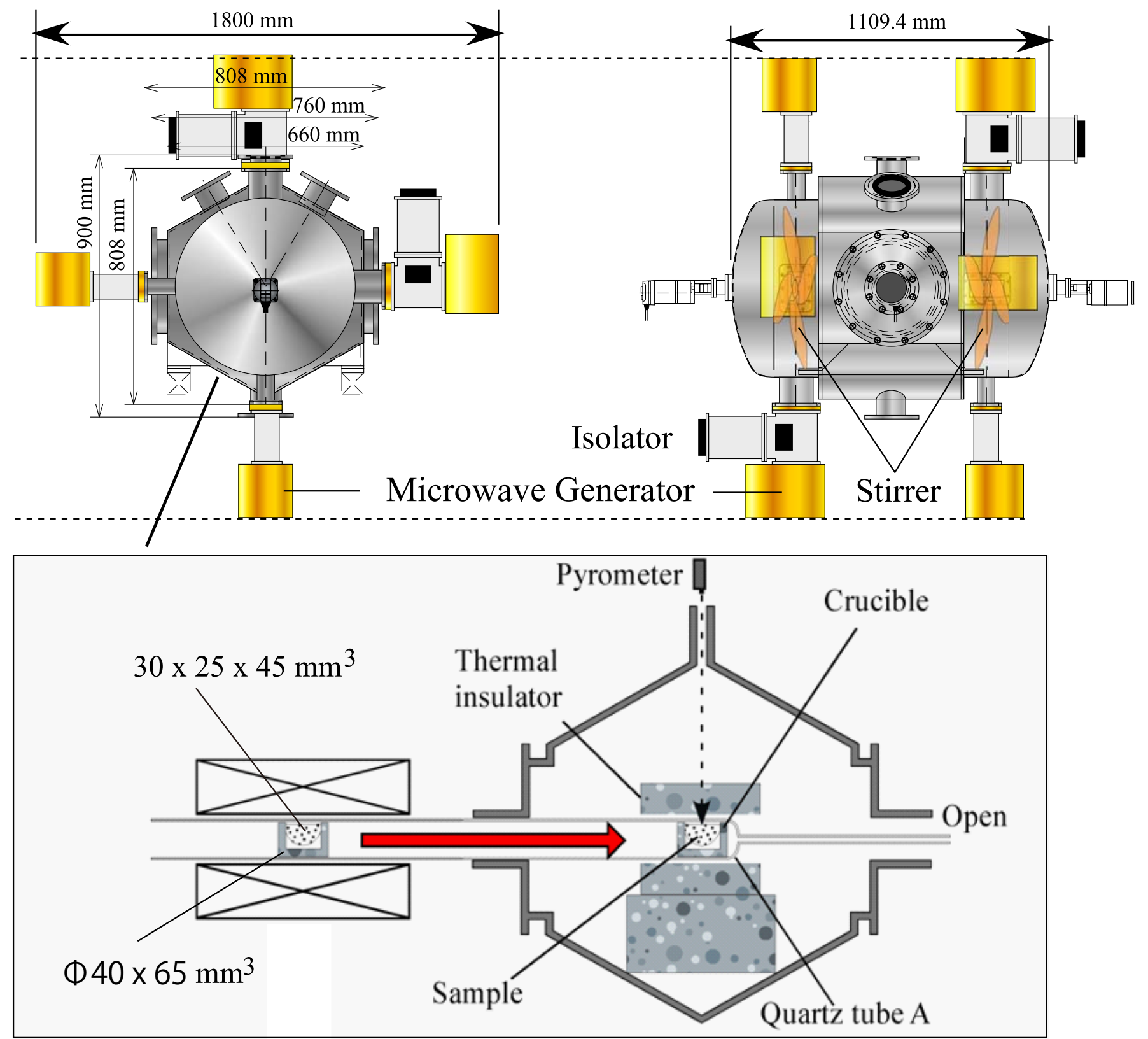
Figure(s)

Click here to download Figure(s): figure3.eps

Fig. 3 Kashimura et al.

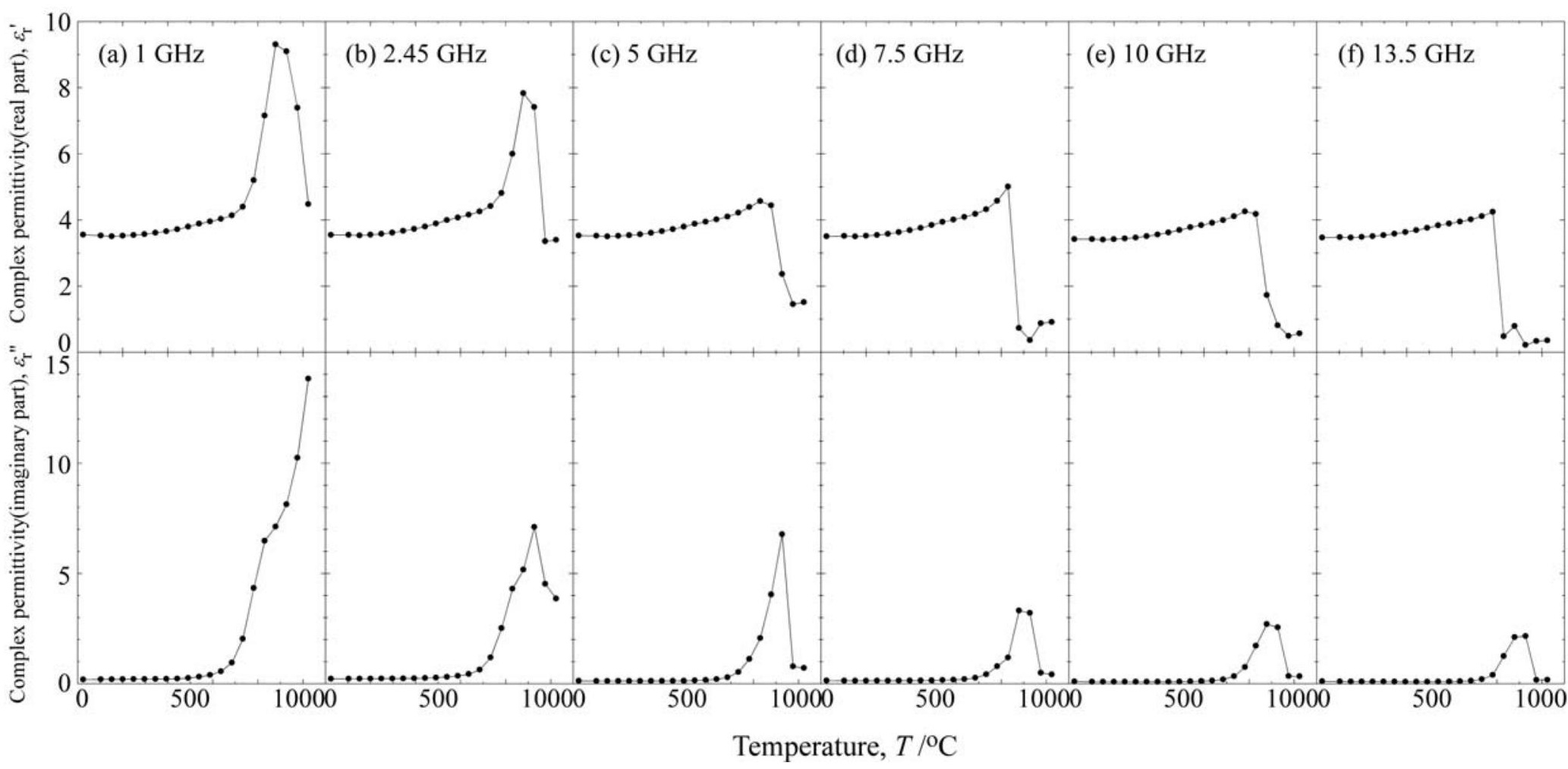


Figure(s)

Click here to download Figure(s): figure4.eps

Figure 4 Kashimura et al.

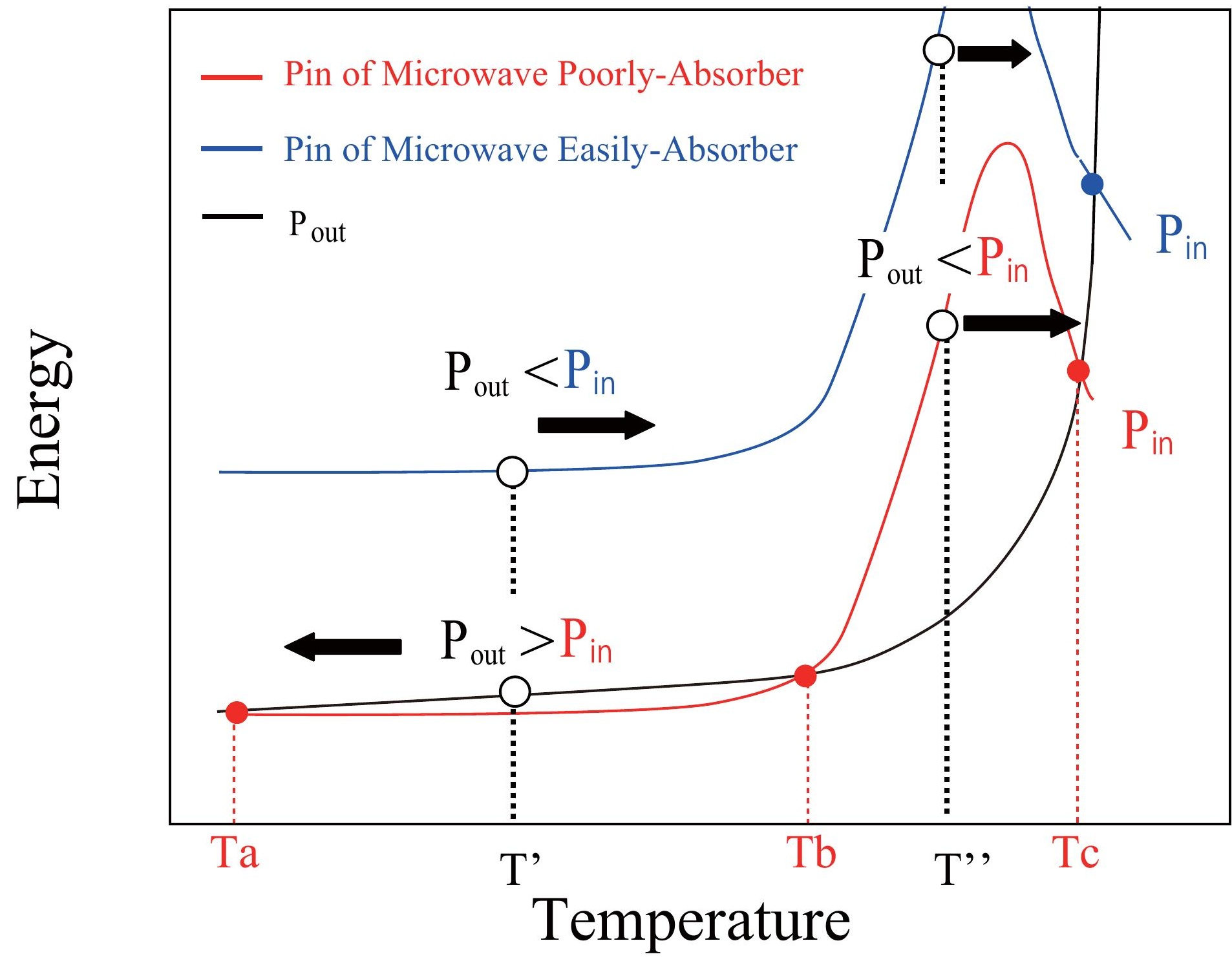


Figure(s)

Click here to download Figure(s): figure5_a.eps

Figure 5 (a) Kashimura et al.

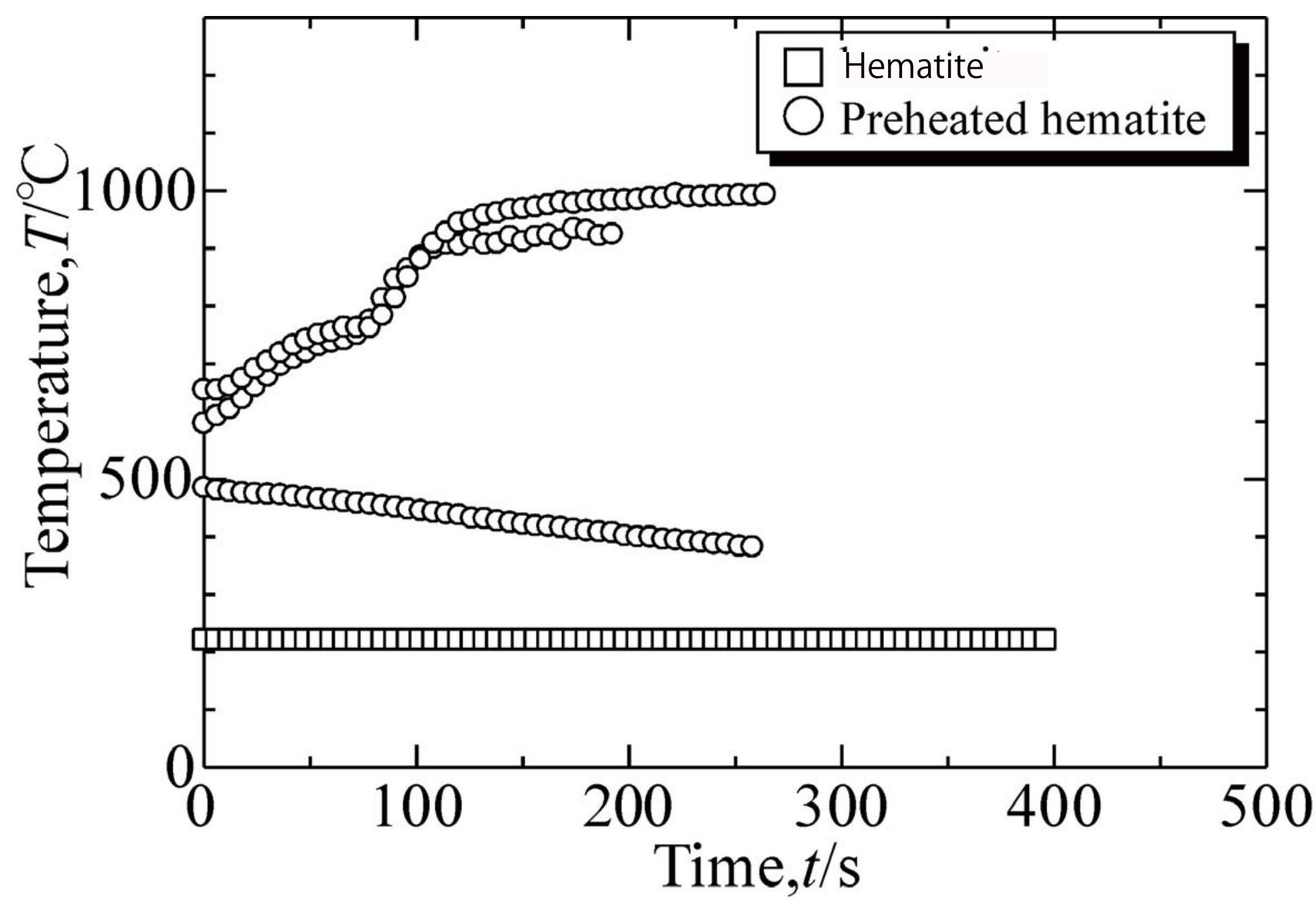


Figure(s)

Click here to download Figure(s): figure5_b.eps

Figure 5 (b) Kashimura et al.

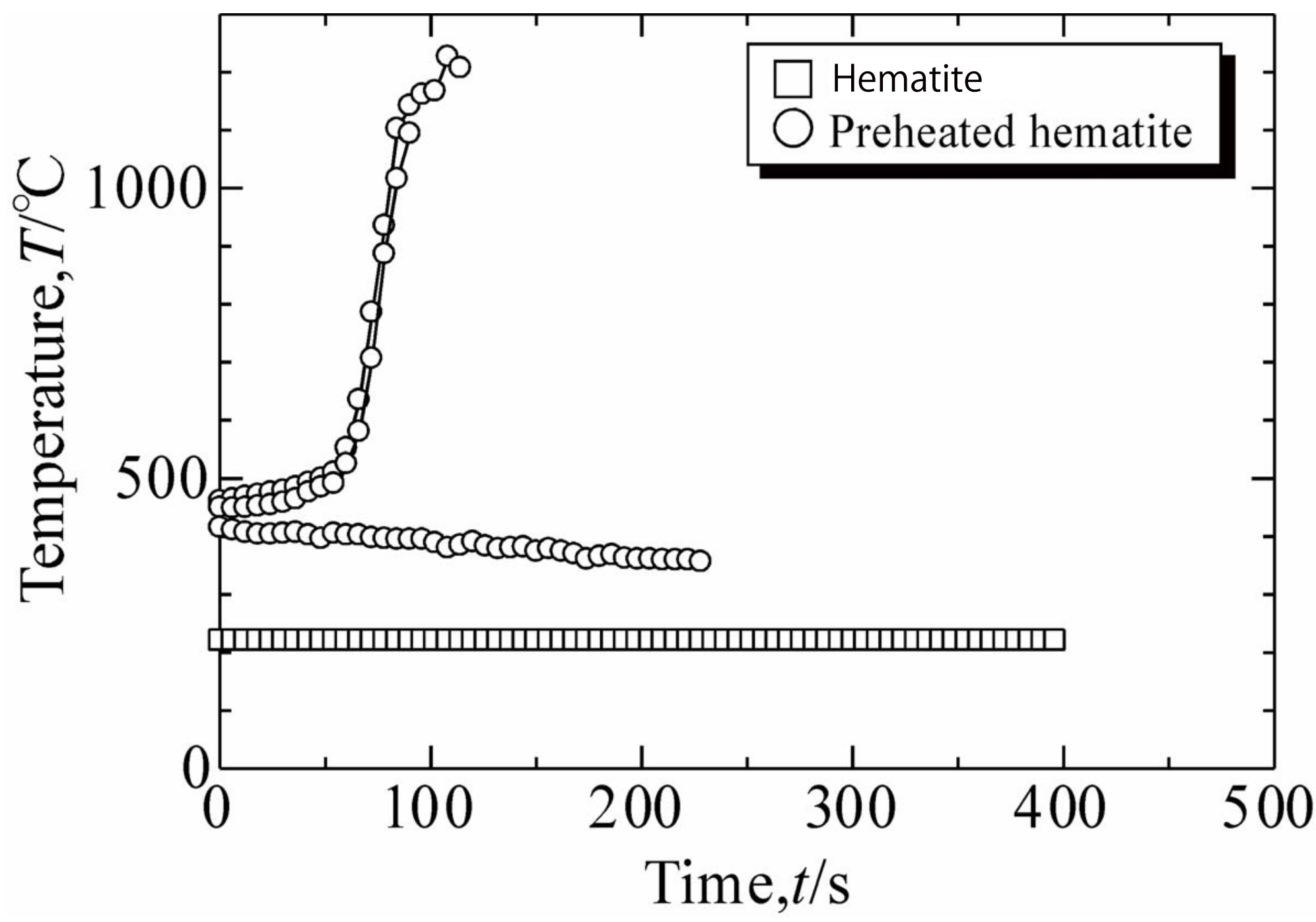


Figure(s)

Click here to download Figure(s): supplmental_figure.eps

Kashimura et al. Supplemental Data

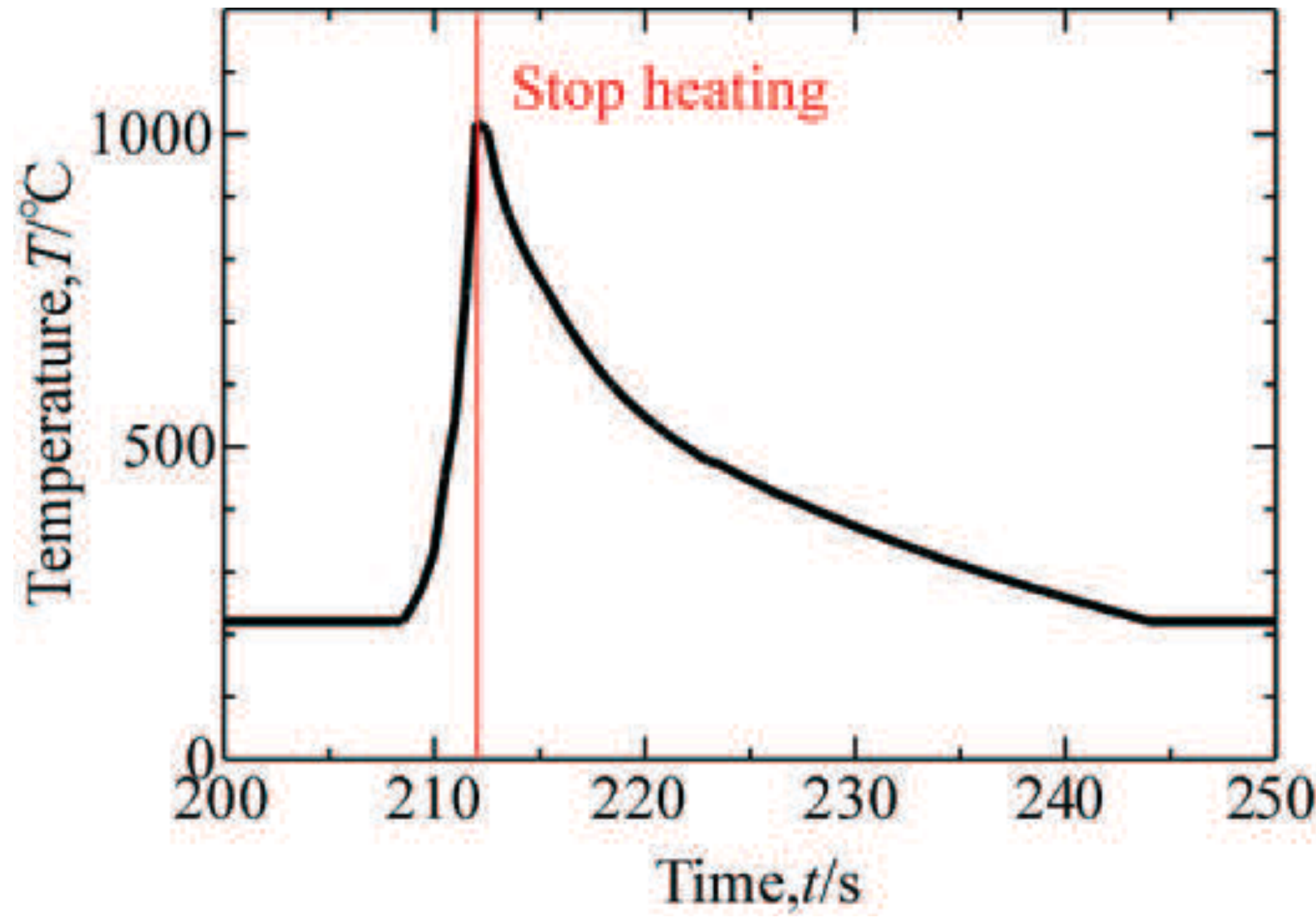

